\title{
Stock Market Fluctuations and the Term Structure
}

\author{
Chunsheng Zhou*
}

July 10,1996

Last Version: January 24, 1996

\footnotetext{
*Federal Reserve Board, Mail Stop 91, Washington, DC 20551. E-mail: czhou@frb.gov. Phone: (202) 452-3328. The views expressed herein are those of the author and do not necessarily reflect those of the Board of Governors of the Federal Reserve System. The author would like to thank John Campbell, Greg Duffee, Mark Fisher, Craig MacKinlay, Matt Pritsker, Robert Stambaugh, and seminar participants at the Federal Reserve Board and the Wharton School for very helpful discussions and comments.
} 


\title{
Stock Market Fluctuations and the Term Structure
}

\begin{abstract}
This paper uses the term structure of interest rates to explain the variations of stock prices and stock returns. It shows that interest rates have an important impact on stock returns, especially at long horizons. The hypothesis that expected stock returns move one-for-one with ex ante interest rates, which has been rejected in other studies using short horizon nominal asset returns, is supported by evidence from real returns and long horizon nominal returns. The paper finds that long-term interest rates explain a major part of variation in dividend-price ratios and suggests that the high volatility of the stock market is related to the high volatility of long-term bond yields and may be accounted for by changing forecasts of discount rates. The findings of this paper may provide a reasonable economic explanation for the predictability of long-horizon stock returns.
\end{abstract}


The term structure of interest rates, which characterizes the movements of riskfree bond yields, is determined by various state variables summarized in the pricing kernel. Observing the term structure of interest rates, or the yield curve, therefore provides information on the pricing kernel and on other assets such as stocks that are priced using the pricing kernel.

However, despite the bond market's information for equity price dynamics, for various reasons, the term structure literature and the equity market literature are not sufficiently well integrated so far, especially in the empirical context. The seminal work on the volatility of the stock market by Shiller (1981) and LeRoy and Porter (1981), for example, assumes constant discount rates. Although economists have noticed the importance of interest rates in predicting the movements of the stock market for years, ${ }^{1}$ few studies have examined the relation between long-horizon stock returns and long-term bond yields.

One set of studies in the literature, including Fama and Schwert (1977), Campbell (1987), Breen, Glosten, and Jagannathan (1989), and Ferson (1989), examines the relation between short-term stock returns and short-term interest rates. These studies typically find that short interest rates have power to forecast short-term stock returns and/or shortterm risk premiums. For example, Fama and Schwert (1977) find that when monthly stock returns are regressed on monthly T-bill rates, the estimated coefficient is significantly negative. Campbell (1987) uses the short-end of the yield curve to predict monthly excess stock returns. He finds that the spread of the two-month and six-month bill over the onemonth bill has predictive power. These studies consider neither the impact of long-term interest rates on the stock market, nor the impact of interest rates on long-term stock returns. The information of the medium- to the long-end of the yield curve is basically ignored in these studies.

Another set of studies, including Fama and French (1989), Fama (1990), Schwert (1990), Campbell and Ammer (1993), and Boudoukh, Richardson, and Whitelaw (1996), uses the term spread-the difference between longer-term and short-term interest rates, to forecast

\footnotetext{
${ }^{1}$ See, for example, Fama and Schwert (1977), Breen, Glosten, and Jagannathan (1989), Keim and Stambaugh (1986), Ferson (1989), Campbell (1987), Campbell and Ammer (1993), Fama (1990), Schwert (1990), Boudoukh, Richardson, and Whitelaw (1996), Shiller and Beltratti (1992), among the others
} 
stock returns or stock risk premiums. The maturities for longer-term rates in these studies are chosen almost arbitrarily, from a few months to as long as a couple of decades, because no theory guides these choices. There is no relation between time horizons of term spreads and time horizons of stock returns forecasted in these studies-the maturities of term spreads are typically much longer than those of stock returns. Fama and French (1989), Fama (1990), and Schwert (1990) document the relation between stock returns and term spreads by OLS regressions. Among a large number of multiple regressions, they find some evidence that term spreads predict short-term stock returns with horizons of one year and less but almost no evidence that term spreads predict longer-horizon stock returns. Campbell and Ammer (1993) use term spreads as information variables to forecast short-horizon stock returns with a linear vector-autoregressive (VAR) approach. They find that real interest rates have very little impact on stock returns. Boudoukh, Richardson, and Whitelaw (1996) examine the relation between excess stock returns and the term spreads over the last two centuries. They find that term spreads (roughly the differences between 20-year bond yield and one-year bond yield) have predictive power for one-year excess stock returns.

This paper extends the literature in two ways. First, it distinguishes itself from other studies by explicitly examining the relation between stock returns and matching maturity bond yields over a wide horizon spectrum so that we can find out if expected stock returns move one-for-one with interest rates at various horizons; second, to investigate the role of varying real discount rates in the stock market volatility, it considers impacts on dividendprice ratios not only of short-term interest rates, but also of medium- to long-term interest rates and pays close attention to the pattern of the maturity structure of interest rates in affecting stock prices.

The paper has many interesting findings. Some of them are listed as follows.

1) The hypothesis that expected stock returns move one-for-one with ex ante interest rates, which is rejected in other studies using short horizon nominal asset returns, is not rejected for real returns and longer-horizon nominal returns.

2) [This finding is closely related to point 1).] Considerable evidence in the literature 
has shown that stock returns are predictable to some extent, especially at long horizons, but there is little consensus on the sources of such predictability. Our finding in 1) about the correlation between stock returns and bond yields may provide a reasonable economic explanation for the predictability of long-horizon stock returns, that is, the predictability of long-horizon stock returns could be associated with predictable changes in long-term interest rates driven by movements in economic conditions such as business cycles.

3) The stock market is very volatile. Recent theoretical work by Cochrane (1992) argues that the variance of dividend-price ratios may be accounted for by changing forecasts of discount rates with some unusual characteristics. Our results demonstrate empirically that the volatility of dividend-price ratios can largely be accounted for by the shifts in the term structure of interest rates and that the volatility of the stock market is closely related to the volatility of long-term bond yields. To summarize, the paper finds that stock market movements are closely related to shifts in the state of the term structure. However, the information in the term structure for stock prices is contained mostly at the medium to long end of the yield curve.

The rest of this paper is arranged as follows. The next section uses the information of the term structure to predict stock returns. It finds that bond yields can account for a considerable part of the variation of stock returns, especially at long horizons. Section 2 provides some empirical results about the role of the term structure in moving the stock market (dividend-price ratios). Section 3 concludes.

\section{Predicting Stock Returns Using the Term Structure of Interest Rates}

As a first attempt to analyze the comovements of stock and bond markets, we study the relation between the required discount rates for the stock market and the bond yields in this section. In particular, we will examine the predictive power of bond yields for stock returns and the well-known hypothesis that expected stock returns move one-for-one with ex ante 
interest rates. For convenience, we will call this hypothesis the excess return hypothesis. ${ }^{2}$

The theoretical foundation of the excess return hypothesis can be described in the following way.

Let $Z_{t, t+n}$ be the gross return on some asset from time $t$ to time $t+n$ and $M_{t, t+n}$ be a random variable known as the pricing kernel or the stochastic discount factor for the corresponding time period. The relationship between $Z_{t, t+n}$ and $M_{t, t+n}$ can be simply described as

$$
1=E_{t}\left[Z_{t, t+n} M_{t, t+n}\right]
$$

Denote $m_{t, t+n}=\log \left(M_{t, t+n}\right)$ and $z_{t, t+n}=\log \left(Z_{t, t+n}\right)$. Taking logarithms of both sides of equation (1) and assuming conditional joint normality of $m_{t, t+n}$ and $z_{t, t+n}$, we have

$$
0=E_{t}\left(m_{t, t+n}+z_{t, t+n}\right)+(1 / 2) \operatorname{Var}_{t}\left(m_{t, t+n}+z_{t, t+n}\right)
$$

Denote $r_{t, t+n}$ as an $n$-period log stock return and $y_{t, t+n}$ as log return to holding an $n$ period bond from $t$ to $t+n$. Applying equation (2) to $r_{t, t+n}$ and $y_{t, t+n}$, after some algebraic manipulations, we have:

$$
E_{t}\left[r_{t, t+n}-y_{t, t+n}\right]=\frac{1}{2}\left[\operatorname{Var}_{t}\left(y_{t, t+n}\right)-\operatorname{Var}_{t}\left(r_{t, t+n}\right)-2 \operatorname{Cov}_{t}\left(r_{t, t+n}-y_{t, t+n}, m_{t, t+n}\right)\right] .
$$

It follows immediately that the hypothesis holds if the expression on the right hand side of the above equation is independent of ex ante interest rate $E_{t}\left[y_{t, t+n}\right]$. In particular, if the second moments on the right hand side are constant though time, the risk premium will also be constant through time.

The existing literature has strongly rejected the hypothesis. For example, Fama and Schwert (1977) shows that when monthly stock returns are regressed on the one-month bill

\footnotetext{
${ }^{2}$ We use this term as the name of the hypothesis because the hypothesis implies that expected excess stock return or risk premium is independent of the corresponding ex ante interest rate. In this paper, the excess stock return (risk premium) over a horizon of $n$ periods is defined as the difference between return to holding the stock portfolio for $n$ periods and the return to holding a riskfree $n$-period bond to the maturity, unless it is explicitly specified in another way.
} 
rate, the estimated coefficient is significantly negative rather than unity as required by the hypothesis. $^{3}$

Existing studies have largely concentrated on short-term asset returns with time-horizons of one-year and less. ${ }^{4}$ However, from a practical perspective, many investors hold stocks for long term investments. The relation between stock returns and bond yields at long horizons is of particular interest here given that results at short horizons are anomalous.

We use the following regression to empirically evaluate the relationship between stock returns and bond yields:

$$
r_{t, t+n}=b_{0}+b_{1} y_{t, t+n}+u_{t, t+n}
$$

where $r_{t, t+n}$ is the ex post log return to holding a stock from time $t$ to time $t+n, y_{t, t+n}$ is the $\log$ return to holding an $n$-period bond from $t$ to $t+n$, and $u_{t, t+n}$ is a stochastic innovation in the stock return. We will pay particular attention to large $n$ to see whether the excess return hypothesis holds at long horizons. If the hypothesis is true at some horizon length $(n)$, then $b_{1}=1$.

\subsection{Data and Summary Statistics}

We now apply equation (4) to postwar U.S. data on stock and bond returns.

Our stock index is the monthly nominal value-weighted index of stocks traded on the NYSE and AMEX, as calculated by the Center for Research in Security Prices (CRSP). The CRSP monthly data set used here runs from 1926 to 1994.

For nominal interest rates, we use McCulloch and Kwon (1993) data set on zero-coupon yields implied by the yield curve for U.S. Treasury securities. This data set has also been used in empirical studies by other authors such as Campbell and Ammer (1993), Campbell and Shiller (1991), and Backus and Zin (1994).

\footnotetext{
${ }^{3}$ Fama (1981), Geske and Roll (1983), and Stulz (1986), among others, have tried to explain this finding as being due to a negative influence of inflation, proxied by the bill rate, on stock returns.

${ }^{4} \mathrm{~A}$ similar argument has been made by Boudoukh and Richardson (1993) on the relationship between nominal asset returns and inflation.
} 
The McCulloch and Kwon data are available at the end of each month from 1946:121991:02, but we drop the observations before 1952:01 in order to avoid the period before the 1951 Treasury-Fed Accord. Since there are only a few monthly observations in 1991, for convenience, we end our sample in 1990:12. Therefore, the data set which we will use actually runs from 1952 to 1990 . In this data set, the first two years are reserved for lags in $\operatorname{VAR}^{5}$ so that our full sample period is 1954:01-1990:12.

To obtain real variables, we deflate nominal variables by the consumption price index (CPI). The inflation rate $\pi_{t, t+n}$ is defined as log change in CPI from time $t$ to time $t+n$. We will use a superscript ' $\$$ ' to express nominal variables henceforth so that we can easily distinguish between real variables and nominal ones. For example, $r_{t, t+n}^{\$}$ will represent nominal stock return from $t$ to $t+n$ while $r_{t, t+n}:=r_{t, t+n}^{\$}-\pi_{t, t+n}$ will represent the corresponding real return. Returns and inflation will be measured in annual rates. A period equals to a month here for monthly observations.

Proper timing is necessary for running regression (5). $y_{t, t+n}^{\$}$ is observable at the end of time $t$, but $r_{t, t+n}^{\$}$ cannot be observed until the end of period $t+n$. For example, if $n=60$ and $t=1990: 12$, then $r_{t, t+n}^{\$}$ cannot be observed until the end of 1995 , which is not in our current CRSP data set yet. To resolve this problem, for a given time horizon $n$, we will choose $t$ such that $t \leq 1990: 12$ and $t+n \leq 1994: 12$.

Table I reports sample means and standard deviations of some key series used in this paper. Several findings in the Table are remarkable.

1) The volatility of stock returns (measured in annual rates) declines very rapidly with time horizons. This finding can be easily justified because $r_{t, t+n}=\sum_{i=0}^{n-1} r_{t+i, t+i+1} / n$. Take $n=2$ as an example. $r_{t, t+2}=\left(r_{t, t+1}+r_{t+1, t+2}\right) / 2$ implies that $\operatorname{Var}\left(r_{t, t+2}\right)=[1+$ $\left.\operatorname{Corr}\left(r_{t, t+1}, r_{t+1, t+2}\right)\right] / 2 \cdot \operatorname{Var}\left(r_{t, t+1}\right)<\operatorname{Var}\left(r_{t, t+1}\right)$.

2) The unconditional standard deviations of interest rates are almost constant over different maturities. This finding is in sharp contrast to the declining volatility of long term stock returns.

\footnotetext{
${ }^{5}$ VAR results are not reported in the current version of paper.
} 
Table I: Summary Statistics for Asset Returns and Inflation. Sample means and standard deviations of nominal stock returns $r_{t, t+n}^{\$}$, nominal interest rates $y_{t, t+n}^{\$}$, real stock returns $r_{t, t+n}$, real interest rates $y_{t, t+n}$, and inflation $\pi_{t, t+n}$. All variables are measured in annual rates.

\begin{tabular}{ccccccccc}
\hline \hline \multicolumn{2}{c}{$n$ (months) } & 1 & 3 & 12 & 24 & 36 & 60 & 96 \\
\hline$r_{t, t+n}^{\$}$ & Mean & 0.108 & 0.108 & 0.107 & 0.104 & 0.103 & 0.102 & 0.100 \\
& S.D. & 0.517 & 0.310 & 0.153 & 0.093 & 0.064 & 0.052 & 0.043 \\
$y_{t, t+n}^{\$}$ & Mean & 0.055 & 0.058 & 0.063 & 0.065 & 0.066 & 0.067 & 0.066 \\
& S.D. & 0.030 & 0.031 & 0.031 & 0.031 & 0.030 & 0.030 & 0.031 \\
$r_{t, t+n}$ & Mean & 0.064 & 0.065 & 0.063 & 0.060 & 0.058 & 0.057 & 0.054 \\
& S.D. & 0.524 & 0.319 & 0.165 & 0.104 & 0.075 & 0.062 & 0.053 \\
$y_{t, t+n}$ & Mean & 0.012 & 0.015 & 0.019 & 0.021 & 0.021 & 0.022 & 0.020 \\
& S.D. & 0.036 & 0.029 & 0.028 & 0.031 & 0.032 & 0.032 & 0.032 \\
$\pi_{t, t+n}$ & Mean & 0.044 & 0.044 & 0.044 & 0.044 & 0.045 & 0.045 & 0.047 \\
& S.D. & 0.042 & 0.036 & 0.031 & 0.029 & 0.027 & 0.025 & 0.023 \\
\hline \hline
\end{tabular}


3) (This point is related to the above two findings.) The short-term stock returns are much volatile than short-term interest rates but the difference of unconditional standard deviations of long-term stock returns and long-term interest rates is not that large.

\subsection{Nominal Stock Returns Versus Nominal Interest Rates}

Equation (4) is so formulated that it can be applied to data in either nominal terms or real terms. We will apply the equation to nominal data first. We are interested in nominal returns here for two reasons. First, in our analysis, bonds are riskfree only in nominal terms so we can only observe the nominal term structure ex ante. Second, many other authors such as Fama and Schwert (1977) and Breen et al. (1989) have studied the relation between nominal stock returns and nominal interest rates over short horizons and found a surprising negative correlation between nominal stock returns and nominal interest rates, so it is nice to know what will happen to the relation (between nominal stock returns and nominal interest rates) over long horizons. Using nominal variables, we can rewrite equation (4) as

$$
r_{t, t+n}^{\$}=b_{0}+b_{1} y_{t, t+n}^{\$}+u_{t, t+n}^{\$}
$$

Table II presents the estimates of regression of long-term nominal stock returns on the matching-maturity nominal bond yields using the postwar data. To generate asymptotically valid standard errors, we use a method outlined by Hansen and Hodrick (1980) to deal with the serial correlation of residuals due to the overlap of observations of multi-period returns, with a modification due to White (1980) that corrects for heteroscedasticity, and a modification due to Newey and West (1987) that insures the variance-covariance matrix is positive definite. These adjusted standard errors are reported in square brackets. Some features in Table II are remarkable.

1) The estimated slopes are always positive and close to one for long horizons (two years or longer) and the null hypothesis $b_{1}=1$ is not rejected in each case.

2) The predictive power of bond yields for stock returns increases with time horizon. $R^{2}$ reaches about $15 \%$ over the five-year horizon and exceeds $25 \%$ over the eight-year horizon. 
Table II: Predicting Nominal Stock Returns Using the Term Structure. Estimates of OLS regression of $n$-period realized nominal returns on nominal bond yields with equal maturities: $r_{t, t+n}^{\$}=b_{0}+b_{1} y_{t, t+n}^{\$}+u_{t, t+n}^{\$}$. The numbers in brackets [] are standard errors adjusted for the residual autocorrelation due to overlap of observations and for heteroscedasticity with the methods of Hansen and Hodrick (1980), White (1980), and Newey-West (1987).

\begin{tabular}{lccccccc}
\hline \hline$n$ (months) & 1 & 3 & 12 & 24 & 36 & 60 & 96 \\
\hline$b_{0}$ & 0.200 & 0.180 & 0.119 & 0.070 & 0.063 & 0.059 & 0.054 \\
& {$[0.047]$} & {$[0.036]$} & {$[0.044]$} & {$[0.032]$} & {$[0.027]$} & {$[0.028]$} & {$[0.027]$} \\
$b_{1}$ & -1.666 & -1.239 & -0.186 & 0.530 & 0.605 & 0.644 & 0.706 \\
& {$[0.821]$} & {$[0.553]$} & {$[0.668]$} & {$[0.395]$} & {$[0.322]$} & {$[0.333]$} & {$[0.269]$} \\
$R^{2}$ & 0.010 & 0.015 & 0.001 & 0.031 & 0.081 & 0.139 & 0.251 \\
\hline \hline
\end{tabular}

This finding suggests that the information of long-maturity bonds should not be ignored when one investigates the comovements of stock and bond markets.

3) Fama and Schwert (1977) and Breen et al. (1989) find that short term (monthly) nominal stock returns are negatively correlated with short term nominal riskfree interest rates. We find very similar results here for short-horizon asset returns. From Table II, we see that the relation between nominal stock returns and nominal interest rates over short horizons is significantly different from that over longer-horizons. This finding provides another piece of evidence that the behavior of financial market over short horizons could be very different from that over longer horizons. ${ }^{6}$

\footnotetext{
${ }^{6}$ Some other related findings are: stock returns are positively auto-correlated over short horizons while negatively auto-correlated over long horizons (e.g., Fama and French 1988a, and Poterba and Summers 1988); stock returns and inflation are negatively correlated over short horizons but positively correlated over long horizons (Fama and Schwert 1977, Breen et al. 1989, Geske and Roll 1983, Schwert 1981, Stulz 1986, Boudoukh and Richardson 1993).
} 


\subsection{Real Stock Returns Versus Real Interest Rates}

Because nominal asset returns are driven by changes in expected inflation, changes in required real discount rates, or both, some interesting questions about Table II naturally arise. Is the covariance between nominal stock returns and nominal interest rates due mostly to an impact of movement in expected inflation, or is it due to the comovement in real (stock and bond) returns? ${ }^{7}$

To answer the above question, we have to consider the relation between real stock returns and real interest rates. For this reason, we now apply equation (4) to real data.

Table III reports estimates of regressions of real stock returns $r_{t, t+n}$ on real interest rates $y_{t, t+n}$. The estimated slopes are positive and are are generally very significant. Especially, the null hypothesis that stock returns move one-for-one with matching-maturity bond returns is not rejected for real returns.

Comparing Table III with Table II, we find the following important differences:

1) The estimated slopes $\left(b_{1}\right)$ for nominal returns in Table II are negative over short horizons, while these slopes for real returns are always positive and significant.

2) The estimated slopes for real rates are much bigger than those for nominal rates. The $R^{2}$ 's for real rates are much higher too.

Though the theoretical relation (4) is ex ante, the regressions of real stock returns on ex post real interest rates reported in Table III nevertheless can be interpreted in the context of this relation. In particular, by recognizing that an ex-post interest rate equals its ex ante rate plus a prediction error, the OLS estimates in Table III could be interpreted as a

\footnotetext{
${ }^{7}$ Stocks are claims against real assets. The dividend stream of stocks is relatively stable in real terms. If the Fisher equality could hold, that is, if the nominal interest rates were merely a proxy for the expected inflation, the term structure of interest rates would almost have nothing to do with the stock market in real terms. Fama (1975) argues that if expected real returns on default-free bonds are constant and the market is efficient, then expected inflation equals to a constant plus the nominal return on the default-free bond. Based on this argument, Fama and Schwert (1977) use the nominal return on some default-free bond over a given period as their measure of expected inflation over the same period. Boudoukh and Richardson (1993) find that nominal stock returns and nominal inflation are positively correlated over long horizons.
} 
Table III: The Ex-post Relation between Real Stock Returns and Real Bond Yields. Estimates of OLS regression of $n$-period realized real returns on real bond yields with corresponding maturities: $r_{t, t+n}=b_{0}+b_{1} y_{t, t+n}+u_{t, t+n}$. The numbers in brackets [] are standard errors adjusted for the residual autocorrelation due to overlap of observations and for heteroscedasticity with the methods of Hansen and Hodrick (1980), White (1980), and Newey-West (1987).

\begin{tabular}{lccccccc}
\hline \hline$n$ (months) & 1 & 3 & 12 & 24 & 36 & 60 & 96 \\
\hline$b_{0}$ & 0.043 & 0.033 & 0.025 & 0.025 & 0.030 & 0.031 & 0.031 \\
& {$[0.026]$} & {$[0.025]$} & {$[0.027]$} & {$[0.022]$} & {$[0.019]$} & {$[0.018]$} & {$[0.017]$} \\
$b_{1}$ & 1.876 & 2.123 & 2.000 & 1.715 & 1.347 & 1.208 & 1.128 \\
& {$[0.737]$} & {$[0.875]$} & {$[0.893]$} & {$[0.560]$} & {$[0.408]$} & {$[0.255]$} & {$[0.281]$} \\
$R^{2}$ & 0.016 & 0.036 & 0.118 & 0.262 & 0.325 & 0.376 & 0.469 \\
\hline \hline
\end{tabular}

regression of real stock returns on ex ante real interest rates in the presence of measurement errors. This leads to the well-known errors-in-variables problem, yielding asymptotically biased estimates of $b_{0}$ and $b_{1}$. One difficulty is that there is no way to determine precisely how large the magnitude of this bias is. As a consequence, it seems natural to consider also regressions in which the inconsistency of the estimates can be corrected.

A straightforward way to correct the inconsistency seems to be the regression of realized stock returns on the ex ante real interest rates. Unfortunately, since bonds are typically riskless in nominal terms, ex ante real interest rates are not observable. In this paper, we overcome the inability to observe ex ante real interest rates by using an instrumental variables (IV) approach. We choose instruments that have good support as measures of ex ante real interest rates. Using ex post real interest rates as proxies for ex ante interest rates, along with instruments, we provide consistent estimates of the ex ante relation between real stock returns and real interest rates.

We now rewrite the normal equations derived from regression (4) in the following IV 
Table IV: On the Choice of the Instrument: Evidence from Correlations. $z_{t}=$ $y_{t-3, t}$ is chosen as the instrumental variable here. This table provides statistical evidence about this choice.

\begin{tabular}{lccccccc}
\hline \hline$n$ (months) & 1 & 3 & 12 & 24 & 36 & 60 & 96 \\
\hline $\operatorname{Corr}\left(z_{t}, y_{t, t+n}\right)$ & 0.482 & 0.580 & 0.643 & 0.597 & 0.558 & 0.555 & 0.514 \\
\hline \hline
\end{tabular}

setting:

$$
E\left[\left(r_{t, t+n}-b_{0}-b_{1} y_{t, t+n}\right) \otimes\left(1, z_{t}\right)\right]=0,
$$

where $\left(1, z_{t}\right)$ is the vector of instrumental variables in which the constant one is always included.

We choose the past real short-term interest rate (of three-month bond), $y_{t-3, t}$, as the instrument $z_{t}$. The choice is strongly motivated by earlier finance work, such as Cox, Ingersoll, Ross (1985) and Vasicek (1977), who characterize interest rates using stochastic processes in which the expected next period interest rate is determined by currently realized interest rate. The choice is also justified by the empirical finding that current interest rates predict future interest rates. From Table IV, we can see that the instrument $y_{t-3, t}$ is correlated with dependent variables $y_{t, t+n}$. The correlations are always close to or higher that 0.50 .

Table V shows the results of instrumental variables (IV) regressions of real stock returns on real interest rates. Comparing this table with Table III, we find that the ex ante relation between real stock returns and real interest rates is similar to the ex post relation: estimated slopes $\left(b_{1}\right)$ are significantly positive and are usually not distinguishable from $1.0 .^{8}$ The evidence here strongly supports the hypothesis that real stock returns move closely together with real interest rates.

Our results in Tables II through V recommend that the excess return hypothesis is not rejected for data over longer horizons. This finding suggests that the term structure of

\footnotetext{
${ }^{8}$ The only exception is that in Table $\mathrm{V}, b_{1}$ is significantly greater than one for monthly returns.
} 
Table V: The Ex-ante Relation between Real Stock Returns and Real Bond Yields. Estimates of IV regression of $n$-period realized real returns on real bond yields with corresponding maturities: $E\left[\left(r_{t, t+n}-b_{0}-b_{1} y_{t, t+n}\right) \otimes\left(1, z_{t}\right)\right]=0$. The past 3 -month real interest rate $z_{t}=y_{t-3, t}$ is used as the instrument here. The numbers in brackets [] are standard errors adjusted for the residual autocorrelation due to overlap of observations and for heteroscedasticity with the methods of Hansen and Hodrick (1980), White (1980), and Newey-West (1987).

\begin{tabular}{lccccccc}
\hline \hline$n$ (months) & 1 & 3 & 12 & 24 & 36 & 60 & 96 \\
\hline$b_{0}$ & 0.010 & 0.012 & 0.013 & 0.025 & 0.029 & 0.029 & 0.040 \\
& {$[0.034]$} & {$[0.031]$} & {$[0.030]$} & {$[0.020]$} & {$[0.016]$} & {$[0.017]$} & {$[0.019]$} \\
$b_{1}$ & 4.681 & 3.584 & 2.523 & 1.699 & 1.392 & 1.276 & 0.700 \\
& {$[1.610]$} & {$[1.389]$} & {$[0.831]$} & {$[0.401]$} & {$[0.253]$} & {$[0.227]$} & {$[0.262]$} \\
\hline \hline
\end{tabular}

interest rates may be very informative about the movement of future stock returns.

\subsection{Some Remarks}

As we mentioned earlier, the negative correlation between nominal stock returns and nominal interest rates over short-horizons has been well documented in the literature and has been typically attributed to the negative influence of inflation. The positive correlation between nominal stock returns and nominal interest rates at longer-horizons could be due both to the positive correlation between nominal returns and inflation ${ }^{9}$ and to the positive correlation between real stock returns and real interest rates. ${ }^{10}$

It is interesting to note that the explanatory power of interest rates for stock returns (returns can be measured in either nominal or real terms), represented by $R^{2}$ of OLS regressions, increases rapidly with time horizons, ${ }^{11}$ even though there is an errors-in-variables

\footnotetext{
${ }^{9}$ See, for example, Boudoukh and Richardson (1993).

${ }^{10}$ See Tables III and V.

${ }^{11}$ The only exception is the explanatory power for nominal returns at short-horizons, but in this case,
} 
problem in OLS regressions of real returns. For example, $R^{2}$ for monthly real returns is less than 2 percent, but is almost 40 percent for 5 -year real returns. It is hard to explain such a dramatic difference by the errors-in-variables problem given that the same issue exists for all time horizons.

A very plausible economic story for that increasing power is that long horizon stock returns are much less volatile than short horizon stock returns while long term interest rates have almost the same variances as short term interest rates, as reported in Table I. When the slopes of interest rates are not very different, interest rates will explain a larger percentage of variations in long-horizons stock returns than variations in short horizon stock returns. Given that the slopes of regressions of real stock returns on ex ante real interest rates (Table $\mathrm{V}$ ) are almost not distinguishable from one, if ex ante interest rates for different maturities also have the similar variances, we can expect that long term ex ante interest rates will have more explanatory power for long-horizon stock returns that short-term ex ante rates do for short-horizon stock returns.

Though there is considerable evidence that stock returns are partially predictable, ${ }^{12}$ the causes of such predictability have yet to be determined. Currently, there are two competing explanations. Some interpret the predictability as evidence of stock market inefficiencies, while others look to time-varying equilibrium expected returns, driven by economic fundamentals. Tables II, III, and V may provide some new insights on this dispute. These tables show that the predictability of stock returns is closely related to the cyclical behavior of the term structure of interest rates and therefore favors a 'stock market efficiency' argument: ${ }^{13}$ the predictability of long-horizon stock returns is possibly driven by predictable changes in long-term interest rates.

nominal stock returns and nominal interest rates are negatively rather than positively correlated.

${ }^{12}$ See, e.g., Bekaert and Hodrick (1992), Campbell (1991), Fama and French (1988a,b), Ferson and Korajczyk (1995), Lo and MacKinlay (1988), and Poterba and Summers (1988), among the others.

${ }^{13}$ In this paper, we do not consider the efficiency of the bond market. 


\section{Stock Market Movements and the Term Structure}

Since stock prices equal the discounted values of expected future dividends, any useful information about stock discount rates, including the information contained in the term structure, should be reflected in stock prices. How do stock prices aggregate the information of the term structure? What role does the term structure play in explaining the variation of stock prices or dividend-price ratios? For practioners, these questions are important because practioners are interested in using the information of the term structure in pricing and investment decisions. For academic economists, these questions are interesting because answering them will help to identify some of the sources of stock market fluctuations and the comovement of equity and bond markets.

In this section, we will empirically investigate how the term structure of interest rates is related to stock market fluctuations. Since stock prices are not stationary, for convenience, we study $\log$ dividend price ratios $d p_{t}:=\ln \left(D_{t} / P_{t}\right)$ instead, where $D_{t}$ is time $t$ dividend and $P_{t}$ is time $t$ stock price. We measure the dividend price ratios on the stock index in a standard way, by taking total dividends paid over the last 12-month period relative to the stock price at the end of the current month.

\subsection{Empirical Results}

To examine the role of interest rates in moving the stock market, we run the following set regressions:

$$
d p_{t}=b_{0}+b_{1} y_{t, t+n}+u_{t}
$$

In the above expression, $y_{t, t+n}$ is tentatively used as a proxy for ex ante real interest rates $E_{t}\left[y_{t, t+n}\right] .{ }^{14}$ Roughly speaking, evidence that $b_{1}>0$ implies that an increase in real interest rates will be associated with a rise in dividend/price ratios. A very possible channel, from our early results, is that an increase in interest rates signals an increase in stock discount rates and as a result, a drop in stock prices.

\footnotetext{
${ }^{14} y_{t, t+n}$ serves as a noisy proxy for $E_{t}\left[y_{t, t+n}\right]$ because $y_{t, t+n}$ is only observed ex post. We will address more details about this point lately.
} 
Table VI: The Relation between Dividend-Price Ratios and Real Interest Rates. OLS estimates of regressions of dividend price ratio $d p_{t}$ on on interest rate variables $y_{t, t+n}$ : $d p_{t}=b_{0}+b_{1} y_{t, t+n}+u_{t}$. The numbers in brackets [] are autocorrelation and heteroscedasticity consistent standard errors obtained with the method of Newey and West (1987).

\begin{tabular}{lccccccc}
\hline \hline$n$ (months) & 1 & 3 & 12 & 36 & 60 & 96 & 120 \\
\hline$b_{0}$ & -3.253 & -3.264 & -3.281 & -3.290 & -3.308 & -3.330 & -3.334 \\
& {$[0.064]$} & {$[0.068]$} & {$[0.077]$} & {$[0.076]$} & {$[0.072]$} & {$[0.054]$} & {$[0.045]$} \\
$b_{1}$ & 0.633 & 1.208 & 1.857 & 2.055 & 2.894 & 4.274 & 4.855 \\
& {$[0.834]$} & {$[1.298]$} & {$[1.478]$} & {$[1.306]$} & {$[1.079]$} & {$[0.704]$} & {$[0.813]$} \\
$R^{2}$ & 0.012 & 0.030 & 0.068 & 0.106 & 0.199 & 0.415 & 0.502 \\
\hline \hline
\end{tabular}

Table VI shows regression results. The parameters are estimated by OLS. The standard errors in brackets, obtained with the method of Newey and West (1987), are autocorrelation and heteroscedasticity consistent. ${ }^{15}$ The Table shows that estimated slopes are always positive (significant for long horizons). This implies that a change in interest rates typically accompanies a change in the dividend-price ratios in the same direction. The table also shows that the power of interest rates in explaining the variation of the stock market varies dramatically with the maturity horizon of the interest rates.

As we mentioned in the introduction, most authors who study the interaction between stock and bond returns only consider short-term interest rates while ignoring the rest of the yield curve. What we learn from Table VI is:

1) Short term interest rates alone contain very little information on the movements of the stock market. The estimates of slopes in the regressions of short-horizon (one-year and

\footnotetext{
${ }^{15}$ As we know dividend-price ratios are highly auto-correlated. Some method is therefore needed to handle this auto-correlation. We do not use a generalized least squares (GLS) approach here because a time-series version of GLS technique requires the strict econometric exogeneity of independent variables. In the current context, this means that knowledge of future interest rate variables could not affect the current stock price or the current dividend-price ratio. This may not be true.
} 
less) stock returns on interest rates are very insignificant and $R^{2} \mathrm{~s}$ in these regressions are very low.

2) Long term interest rates generally play an important role in stock market fluctuations. The estimates of slopes are very significant for long term interest rates (five-year and longer). Ten-year interest rates alone can account for about half of the variance of $\log \mathrm{D} / \mathrm{P}$ ratios.

A major concern about the results in Table VI is the distinction between ex post interest rates and ex ante rates. Theoretically, stock prices and $\mathrm{D} / \mathrm{P}$ ratios are determined by ex ante variables-expected future cash flow and expected future discount rates. As we mentioned earlier, if the movements in the stock market are related to real interest rates, the relevant interest rates should be ex ante rates rather than ex post rates. However, because ex ante real rates are not observable, we use ex post rates as proxies for ex ante rates as we did in the last section. By recognizing that an ex post rate equals its ex ante rate plus a prediction error, we have an errors-in-variables problem similar to that in Table III. In that case, we use an IV approach to asymptotically correct measurement errors. Can we use the same IV approach to resolve the errors-in-variables problem again?

Assume that the true relation between $\mathrm{D} / \mathrm{P}$ ratios and interest rates $y_{t, t+n}$ is

$$
d p_{t}=a_{0}+a_{1} E_{t}\left[y_{t, t+n}\right]+u_{n t}
$$

Because $E_{t}\left[y_{t, t+n}\right]$ is not observed by econometricians, one may want to make an asymptotically unbiased estimate of $a_{1}$ with an instrumental variables (IV) approach based on the following relation:

$$
E\left[\left(d p_{t}-a_{0}-a_{1} y_{t, t+n}\right) \otimes\left(1, z_{t}\right)\right]=0
$$

To obtain a consistent estimate of coefficient $a_{1}$, the instrument $\left(z_{t}\right)$ should 1 ) be correlated with $\left.E_{t}\left[y_{t, t+n}\right] ; 2\right)$ be uncorrelated with the prediction error in real interest rate $E_{t}\left[y_{t, t+n}\right]-y_{t, t+n}$; and 3 ) be uncorrelated with residual term $u_{n t}$ in relation (8).

It is easy to find instruments which satisfy the first two conditions, but it is really hard to find an instrument which satisfies the third condition. For example, the instrument used in Table V, $y_{t-3, t}$, satisfies the first two conditions but may not satisfy the third one. To 
see this, let's consider two interest rates with different maturities $y_{t, t+m}$ and $y_{t, t+n}(m \neq n)$. Theoretically, both $E_{t}\left[y_{t, t+m}\right]$ and $E_{t}\left[y_{t, t+n}\right]$ are likely to contain information about future stock discount rates. If one rate, say $E_{t}\left[y_{t, t+m}\right]$, has additional power to explain the variation of $\mathrm{D} / \mathrm{P}$ ratios beyond another rate, say $E_{t}\left[y_{t, t+n}\right]$, then $E_{t}\left[y_{t, t+m}\right]$ will be correlated with residual $u_{n t}$. An instrument such as $y_{t-3, t}$ which is correlated with future interest rate $E_{t}\left[y_{t, t+m}\right]$, is possibly also correlated with $u_{n t}$. The third condition is therefore likely to be violated.

The above argument tells us that the instrumental variables approach may not be appropriate to solve the errors-in-variables problem here. Can we still interpret the relations between interest rates and $\mathrm{D} / \mathrm{P}$ ratios reported in Table VI rigorously? To answer this question, we need to know if the OLS coefficients in the Table are downward-biased or upward-biased.

Denote $e_{n t}:=y_{t, t+n}-E_{t}\left[y_{t, t+n}\right]$. If economic agents have rational expectations, then

$$
\operatorname{Cov}\left(e_{n t}, E_{t}\left[y_{t, t+n}\right]\right)=0
$$

By the formula of OLS projection, $a_{1}$ in equation (8) is given by

$$
a_{1}=\operatorname{Var}\left(E_{t}\left[y_{t, t+n}\right]\right)^{-1} \operatorname{Cov}\left(E_{t}\left[y_{t, t+n}\right], d p_{t}\right)
$$

while $b_{1}$ in equation (7) can be written as

$$
b_{1}=\operatorname{Var}\left(y_{t, t+n}\right)^{-1} \operatorname{Cov}\left(y_{t, t+n}, d p_{t}\right) .
$$

Because $\operatorname{Cov}\left(e_{n t}, E_{t}\left[y_{t, t+n}\right]\right)=0$, we have

$$
\operatorname{Var}\left(y_{t, t+n}\right)=\operatorname{Var}\left(E_{t}\left[y_{t, t+n}\right]\right)+\operatorname{Var}\left(e_{n t}\right)>\operatorname{Var}\left(E_{t}\left[y_{t, t+n}\right]\right)
$$

Also, because $d p_{t}$ is in economic agents' time $t$ information set, $E\left[e_{n t} \mid d p_{t}\right]=0$ and therefore

$$
\operatorname{Cov}\left(y_{t, t+n}, d p_{t}\right)=\operatorname{Cov}\left(E_{t}\left[y_{t, t+n}\right], d p_{t}\right)+\operatorname{Cov}\left(e_{n t}, d p_{t}\right)=\operatorname{Cov}\left(E_{t}\left[y_{t, t+n}\right], d p_{t}\right)
$$

As a result, the inequality

$$
b_{1}<a_{1}
$$


holds as long as $\operatorname{Cov}\left(y_{t, t+n}, d p_{t}\right)>0$. This implies that OLS estimates of slopes $\left(b_{1}\right)$ in Table VI are downward biased from their corresponding true values $\left(a_{1}\right)$ in expression (8). The results in Table VI suggest that there should be an even stronger positive relation between ex ante real interest rates and dividend/price ratios.

Table VI shows that OLS regressions of $\log \mathrm{D} / \mathrm{P}$ ratios on ex post long-term real interest rates generate very high $R^{2}$ s. Does this imply that ex ante interest rates can account for a large portion of variations in $\mathrm{D} / \mathrm{P}$ ratios?

Denote $R_{p}^{2}$ as the true value of $R^{2}$ implied by the ex post relation (7) and $R_{a}^{2}$ as $R^{2}$ implied by the ex ante relation (8). By definition, we have

$$
\begin{aligned}
R_{p}^{2} & =\frac{\operatorname{Cov}\left(y_{t, t+n}, d p_{t}\right)^{2}}{\operatorname{Var}\left(y_{t, t+n}\right) \cdot \operatorname{Var}\left(d p_{t}\right)} \\
& =\frac{\operatorname{Cov}\left(E_{t}\left[y_{t, t+n}\right], d p_{t}\right)^{2}}{\operatorname{Var}\left(y_{t, t+n}\right) \cdot \operatorname{Var}\left(d p_{t}\right)}, \\
R_{a}^{2} & =\frac{\operatorname{Cov}\left(E_{t}\left[y_{t, t+n}\right], d p_{t}\right)^{2}}{\operatorname{Var}\left(E_{t}\left[y_{t, t+n}\right]\right) \cdot \operatorname{Var}\left(d p_{t}\right)} .
\end{aligned}
$$

$\operatorname{Var}\left(y_{t, t+n}\right)>\operatorname{Var}\left(E_{t}\left[y_{t, t+n}\right]\right)$ implies that

$$
R_{a}^{2}>R_{p}^{2}
$$

That is, th ex ante rates are even more powerful to explain the variations in $\mathrm{D} / \mathrm{P}$ ratios. Define $V R(n):=\operatorname{Var}\left(E_{t}\left[y_{t, t+n}\right]\right) / \operatorname{Var}\left(y_{t, t+n}\right)$ as the variance ratio of expected interest rate $E_{t}\left[y_{t, \boldsymbol{t}+\boldsymbol{n}}\right]$ over ex post rate $y_{t, t+n}$. It follows immediately from the above results that $0<V R(n)<1$ and that

$$
R_{a}^{2}=[1 / V R(n)] \cdot R_{p}^{2}
$$

The $R^{2}$ s reported in Table VI are estimated values of $R_{p}^{2}$. The already high $R^{2} \mathrm{~s}$ of regressions of $\mathrm{D} / \mathrm{P}$ ratios on long-term ex post real interest rates suggest that ex ante real interest rates can explain a very significant part of the squared variation in $\log \mathrm{D} / \mathrm{P}$ ratios. For example, 10-year ex ante real interest rates may explain more than half of the squared variance of $\log \mathrm{D} / \mathrm{P}$ ratios. According to relation (9), if $V R(n)=2 / 3$ for the 10 -year horizon, then 10 -year ex ante real interest rates could explain as high as $50.2 \cdot(3 / 2)=75.3$ 
percent of the squared variance of $\log \mathrm{D} / \mathrm{P}$ ratios. A drop in $V R(n)$ will make interest rates more powerful in explaining the variation in the stock market.

\subsection{Interpreting Empirical Results}

The above empirical results suggest strongly that the stock market is correlated with the term structure of interest rates. There are two important questions regarding these results. First, why the explanatory power of interest rates for $\mathrm{D} / \mathrm{P}$ ratios increases with the length of bond maturities? Second, what economic forces drive these results?

We now try to present a reasonable economic story about the first question.

According to the present value relation, $\log \mathrm{D} / \mathrm{P}$ ratios can be approximately expressed as (Campbell and Shiller 1988):

$$
d p_{t}=c-E_{t} \sum_{j=0}^{\infty} \rho^{j}\left[\Delta d_{t+1+j}\right]+E_{t} \sum_{j=0}^{\infty} \rho^{j} r_{t+1+j}
$$

where $\Delta d_{t+1+j}$ is $\log$ real dividend growth from time $t+j$ to time $t+1+j, r_{t+1+j}:=r_{t+j, t+1+j}$ is one-period $\log$ real stock return from $t+j$ to $t+1+j$, and $\rho$ is a positive constant.

A 'temporary' change in expected interest rates often has a small impact on dividend yields while a 'permanent' change can have a large effect. To see this point more intuitively, we can consider a simple example. Let's say that a temporary change in interest rates is a $\xi$ percent increase in yearly interest rates in the first 5 years and that a permanent change in interest rates is an $\eta$ percent increase in yearly interest rates after the fifth year. Assume that expected real stock returns move one-for-one with ex ante real interest rates and that $\rho=0.95$. Ignoring other factors, we have

$$
\begin{aligned}
& \frac{\partial d p}{\partial \xi}=\sum_{j=0}^{4} \rho^{j}=4.5 \\
& \frac{\partial d p}{\partial \eta}=\sum_{j=5}^{\infty} \rho^{j}=15.5
\end{aligned}
$$

This example shows that $\log \mathrm{D} / \mathrm{P}$ ratios are much more sensitive to permanent changes in expected interest rates. 
Roughly speaking, expected interest rates over relatively short horizons $\left(E_{t}\left[y_{t, t+n}\right]\right.$ with small $n$ ) are more likely to be associated with changes in expected stock discount rates in the near future-the temporary changes in expected stock discount rates; while expected interest rates $E_{t}\left[y_{t, t+n}\right]$ with relatively large $n$ are more likely to be associated with longterm trend, or permanent changes in expected stock discount rates. For this reason, the sensitivity of dividend yields to changes in expected interest rates $E_{t}\left[y_{t, t+n}\right]$ increases with time horizon $n$. As a result, long-term interest rates are more powerful for explaining variations in $\mathrm{D} / \mathrm{P}$ ratios.

The coefficient estimates reported in Table VI confirm our story. The slope of the regression of $\log$ dividend-price ratios on real interest rates $\left(b_{1}\right)$ increases with the maturity horizon of interest rates. Ignoring the effect of measurement errors, we can roughly say, for example, that one percent increase in the three-year real interest rate will lead to a two-unit increase in $\log \mathrm{D} / \mathrm{P}$ ratios while a same amount increase in the ten-year interest rate will lead to a five-unit increase in $d p$.

As for the second question, there are roughly two possible interpretations of the comovements of the stock market and the shape of the term structure. First, the expected return to the stock market over a given holding period moves with the expected return to holding an equivalent-maturity bond. Because the discount rate that prices the bond varies, the stock market varies. Second, the expected return to the stock market over certain holding period has a time-varying risk premium over an equivalent-maturity bond, but empirically this premium is correlated with a measure of the shape of the term structure. The distinction here is useful for the way we should think about the stock market.

If we look at the above issue from a long-term perspective, according to the results of section 1, expected stock returns move almost one-for-one with ex ante interest rates. Therefore the long horizon risk premium may not be sufficiently variable to explain the high volatility of the stock market. Also, from Table VI, we see that long term interest rates explain a large portion of squared variations in $\mathrm{D} / \mathrm{P}$ ratios. All the evidence suggests that, from a long-term perspective, the stock market varies with the bond market because stock 
returns move one-for-one with long term interest rates and long-term interest rates vary through time.

On the other hand, we may also look at the issue from a short-horizon perspective. In this case, risk premium moves in the opposite direction with inflation and nominal interest rates. Moreover, Campbell and Ammer (1993) and Cochrane (1992) show that a changing risk premium over short-term debt is necessary to explain the stock market behavior. Based on these previous results, a reasonable way to justify our results about the comovements of the stock market and the bond market in terms of short-term discount rates is that the risk premium of the stock market is correlated with some measure of the term structure.

Can the above two seemingly different (grammar ??) stories be reconciled? The answer is yes. The two interpretations are not contradictory because they are motivated from different perspectives. As a matter of fact, we may decompose long horizon asset returns as the sum of short rates and excess asset returns over short bonds like in Campbell and Ammer (1993):

$$
\begin{aligned}
E_{t}\left[r_{t, t+n}\right] & \equiv E_{t}\left[\sum_{j=1}^{n} r_{t+j}\right] \\
& =E_{t}\left[\sum_{j=1}^{n} y_{t+j}\right]+E_{t}\left[\sum_{j=1}^{n} e_{t+j}\right] \\
E_{t}\left[y_{t, t+n}\right] & \equiv E_{t}\left[\sum_{j=1}^{n} x_{n-1+j, t+j-1, t+j}\right] \\
& =E_{t}\left[\sum_{j=1}^{n} y_{t+j}\right]+E_{t}\left[\sum_{j=1}^{n} e_{n-1+j, t+j-1, t+j}^{b}\right] .
\end{aligned}
$$

where $e_{t+j}:=r_{t+j}-y_{t+j}$ is one-period excess stock return, $x_{n-1+j, t+j-1, t+j}$ is one-period real return on an $n-1+j$-period bond held from $t+j-1$ to $t+j$, and $e_{n-1+j, t+j-1, t+j}^{b}:=$ $x_{n-1+j, t+j-1, t+j}-y_{t+j}$ is one period excess return on an $n-1+j$-period bond.

$E_{t}\left[\sum_{j=1}^{n} e_{t+j}\right]$ is a measure of expected short-term excess stock returns or short-term stock risk premiums; while $E_{t}\left[\sum_{j=1}^{n} e_{n-1+j, t+j-1, t+j}^{b}\right]$ reflects the difference between expected long term interest rates and future short rates, or the shape of the term structure. If ex ante stock return $E_{t}\left[r_{t, t+n}\right]$ moves closely with long-term interest rate $E_{t}\left[y_{t, t+n}\right]$, then 
$E_{t}\left[\sum_{j=1}^{n} e_{t+j}\right]$ may also move closely with $E_{t}\left[\sum_{j=1}^{n} e_{n-1+j, t+j-1, t+j}^{b}\right]$. Put it another way, the notion that long-term expected stock discount rates move one-for-one with long-term ex ante interest rates is not contradictory at all with the notion that short-term stock risk premiums are time varying and are correlated with some measure of the shape of the term structure. Especially, if long-horizon stock risk premium, $E_{t}\left[r_{t, t+n}-y_{t, t+n}\right]$ is constant through time, $E_{t}\left[\sum_{j=1}^{n} e_{t+j}\right]-E_{t}\left[\sum_{j=1}^{n} e_{n-1+j, t+j-1, t+j}^{b}\right]$ must also be a constant.

\section{Concluding Remarks}

This paper uses the term structure of interest rates to explain the variations of stock prices and stock returns. It shows that interest rates have an important impact on stock returns, especially at long horizons. A regression of 8-year real stock returns on ex post real bond yields with the corresponding maturity produces an $R^{2}$ of as high as $47 \%$. The hypothesis that expected stock returns move one-for-one with ex ante interest rates is not rejected over long horizons.

The paper also shows that long-term real interest rates explain a significant part of variation in dividend-price ratios. For example, a 10-year ex ante real interest rate may explain more than half of squared variance of $\log \mathrm{D} / \mathrm{P}$ ratios. This finding suggests that the high volatility of the stock market is related to the high volatility of long-term bond yields. Results in this paper should motivate research that will lead to a better understanding of the relationship between monetary policy, interest rates, and stock returns. 


\section{References}

[1] Bacus, D.K. and S.E. Zin (1994): "Reverse engineering the yield curve," Manuscript, New York University.

[2] Barsky, R.B.(1989): "Why don't the prices of stocks and bonds move together?" American Economic Review 79, 1132-1145.

[3] Bekaert, G. and R.J. Hodrick(1992): "Characterizing Predictable Components in Excess Returns on Equity and Foreign Exchange Markets," Journal of Finance 47, 467509.

[4] Boudoukh, J. and M. Richardson(1993): "Stock returns and inflation: A long horizon perspective," American Economic Review 83, 1346-1355.

[5] Breen, W., L.R. Glosten, and R. Jagannathan(1989): "Economic significance of predictable variations in stock index returns," Journal of Finance 44, 1177-1190.

[6] Campbell, J.Y.(1987): "Stock returns and the term structure," Journal of Financial Economics 18, 373-400.

[7] Campbell, J.Y.(1991): “A variance decomposition for stock returns," Economic Journal 101, 157-179.

[8] Campbell, J.Y.(1995): "Some lessons from the yields curve," Journal of Economic Perspectives 9: 129-152.

[9] Campbell, J.Y. and J. Ammer(1993): "What moves the stock and bond market? A variance decomposition for long-term asset returns," Journal of Finance 48, 3-37.

[10] Campbell, J.Y., A.W. Lo, and A.C. MacKinlay(1996): The Econometrics of Financial Markets, Princeton, N.J.: Princeton University Press, forthcoming.

[11] Campbell, J.Y. and R. Shiller(1988a): "The dividend-price ratio and expectations of future dividends and discount factors," The Review of Financial Studies 1, 195-228. 
[12] Campbell, J.Y. and R. Shiller(1988b): "Stock prices, earnings, and expected dividends," Journal of Finance 43, 661-676.

[13] Campbell, J.Y. and R. Shiller(1991): "Yield spreads and interest rates movements, a bird's eye view," Review of Economic Studies 58, 495-514.

[14] Cochrane, J.H.(1991): "Volatility tests and market efficiency: A review essay," Journal of Monetary Economics 27, 463-485.

[15] Cochrane, J.H.(1992): "Explaining the variance of price-dividend ratios," The Review of Financial Studies 5, 243-280.

[16] Conrad, J. and G. Kaul(1988): "Time-variation in expected returns," Journal of Business $61,409-425$.

[17] Cox, J., J. Ingersoll, and S. Ross(1985): “A theory of the term structure of interest rates," Econometrica 53, 385-407.

[18] Culter, D.M., J.M. Poterba, and L.H. Summers(1989): “What moves stock prices?" Journal of Portfolio Management 15, 4-12.

[19] Fama, E.F.(1981): "Stock returns, real activity, inflation and money," American Economic Review 71, 545-565.

[20] Fama, E.F. and K.R. French(1988a): "Permanent and temporary components of stock prices," Journal of Political Economy 96, 246-273.

[21] Fama, E.F. and K.R. French(1988b): "Dividend yields and expected stock returns," Journal of Financial Economics 22, 3-25.

[22] Fama, E.F. and K.R. French(1989): "Business conditions and expected returns on stocks and bonds," Journal of Financial Economics 25, 23-49.

[23] Fama, E.F. and G.W. Schwert(1977): "Asset returns and inflation," Journal of Financial Economics 5, 115-146. 
[24] Ferson, W.E.(1989): "Changes in expected security returns," Journal of Finance 44, 1191-1217.

[25] Ferson, W.E. and R.A. Korajczyk(1995): "Do arbitrage pricing models explain the predictability of stock returns?" Journal of Business 68, 309-349.

[26] Geske, R. and R. Roll(1983): “The fiscal and monetary linkage between stock returns and inflation," Journal of Finance 38, 1-33.

[27] Hansen, L.P. and R.J. Hodrick(1980): "Forward exchange rates as optimal predictors of future spot rates: An econometric analysis," Journal of Political Economy 88, 829-853.

[28] Hansen, L.P. and K.J. Singleton(1983): "Stochastic consumption, risk aversion, and the temporary behavior of asset prices," Journal of Political Economy 96, 246-273.

[29] Jegadeesh, N.(1990): "Evidence of predictable behavior of stock returns," Journal of Finance 45, 881-898.

[30] Kandel, S. and R. Stambaugh(1988): “Modeling expected stock returns for long and short horizons," Rodney L. White Center Working Paper, No. 42-88, Wharton School, University of Pennsylvania.

[31] Kothari, S.P. and J. Shanken(1992): "Stock return variation and expected dividends: A time-series and cross-sectional analysis," Journal of Financial Economics 31, 177-210.

[32] Keim, D.B. and R.B. Stambaugh(1986): "Predicting returns in the stock and bond markets," Journal of Financial Economics 17, 357-390.

[33] Lo, A.W. and A.C. MacKinlay(1988): "Stock market prices do not follow random walks: Evidence from a simple specification test," The Review of Financial Studies 1, 41-66.

[34] Mankiw, N.G., D. Romer, and M.D. Shapiro(1985): “An unbiased reexamination of stock market volatility," The Journal of Finance 40, 677-687. 
[35] McCulloch, J.H. and H.-L. Kwon(1993): “U.S. term structure data, 1947-1991," Working Paper 93-6, Ohio State University.

[36] Newey, W.K. and K.D. West(1987): “A simple, positive definite, Heteroscedasticity and autocorrelation consistent covariance matrix," Econometrica 55, 703-708.

[37] Poterba, J.M. and L.H. Summers(1988): "Mean reversion in stock prices: Evidence and implications," Journal of Financial Economics 22, 27-59.

[38] Schwert, G.W.(1981): "The adjustment of stock prices to information about inflation," Journal of Finance 36, 15-29.

[39] Shiller, R.J.(1979): "The volatility of long-term interest rates and expectations models of term structure," Journal of Political Economy 87, 1190-1219.

[40] Shiller, R.J.(1981): "Do stock prices move too much to be justified by subsequent changes in dividends?" American Economic Review 71, 421-435.

[41] Shiller, R.J.(1989): Market Volatility, MIT press, Cambridge, Massachusetts.

[42] Shiller, R.J. and A.E. Beltratti(1992): "Stock prices and bond yields: Can their comovements be explained in terms of present value models?" Journal of Monetary Economics 30, 25-46.

[43] Singleton, K.J.(1980): "Expectations models of the term structure and implied variance bounds," Journal of Political Economy 88: 1159-1176.

[44] Stulz, R.M.(1986): "Asset pricing and expected inflation," Journal of Finance 41, 209-223.

[45] Summers, L.H.(1986): "Does the stock market rationally reflect fundamental values?" Journal of Finance 41, 591-601.

[46] Vasicek, O.(1977): "An equilibrium characterization of the term structure," Journal of Financial Economics 5, 177-188. 
[47] West, K.D.(1988): "Dividend innovations and stock price volatility," Econometrica 56, $37-61$.

[48] White, H.(1980): “A heteroscedasticity-consistent covariance matrix estimator and a direct test for heteroscedasticity," Econometrica 48, 817-838. 